\title{
Impact of prostate cancer testing: an evaluation of the emotional consequences of a negative biopsy result
}

\author{
RC Macefield', C Metcalfe', JA Lane', JL Donovan', KNL Avery', JM Blazeby', L Down', DE Neal', FC Hamdy ${ }^{3}$ \\ and K Vedhara*,4, on behalf of the ProtecT Study Group \\ 'Department of Social Medicine, University of Bristol, Canynge Hall, 39 Whatley Road, Bristol BS8 2PS, UK; ' University Department of Oncology, \\ Addenbrooke's Hospital, Hills Road, Cambridge CB2 OQQ, UK; ${ }^{3}$ Nuffield Department of Surgery, University of Oxford, John Radcliffe Hospital, Oxford \\ OX3 9DU, UK; ${ }^{4}$ I-WHO, University of Nottingham, International House, Jubilee Campus, Wollaton Road, Nottingham NG8 IBB, UK
}

\begin{abstract}
BACKGROUND: When testing for prostate cancer, as many as $75 \%$ of men with a raised prostate-specific antigen (PSA) have a benign biopsy result. Little is known about the psychological effect of this result for these men.

METHODS: In all, 330 men participating in the prostate testing for cancer and treatment (ProtecT) study were studied; aged 50-69 years with a PSA level of $\geqslant 3 \mathrm{ng} \mathrm{ml}^{-1}$ and a negative biopsy result. Distress and negative mood were measured at four time-points: two during diagnostic testing and two after a negative biopsy result.

RESULTS: The majority of men were not greatly affected by testing or a negative biopsy result. The impact on psychological health was highest at the time of the biopsy, with around 20\% reporting high distress (33 out of I 7 I) and tense/anxious moods (35 out of I 80). Longitudinal analysis on 195 men showed a significant increase in distress at the time of the biopsy compared with levels at the PSA test (difference in Impact of Events Scale (IES) score: 9.47; 95\% confidence interval (CI) (6.97, I2.12); P<0.00I). These levels remained elevated immediately after the negative biopsy result (difference in score: $7.32 ; 95 \% \mathrm{Cl}(5.5 \mathrm{I}, 9.52) ; P<0.00 \mathrm{I})$ and I2 weeks later (difference in score: $2.42 ; 95 \% \mathrm{Cl}(0.50,1.15) ; P=0.009)$. Psychological mood at the time of PSA testing predicted high levels of distress and anxiety at subsequent time-points.

CONCLUSIONS: Most men coped well with the testing process, although a minority experienced elevated distress at the time of biopsy and after a negative result. Men should be informed of the risk of distress relating to diagnostic uncertainty before they consent to PSA testing.

British Journal of Cancer (2010) I 02, I335-1340. doi: I0.1038/sj.bjc.6605648 www.bjcancer.com

Published online 6 April 2010

(c) 2010 Cancer Research UK
\end{abstract}

Keywords: PSA testing; prostate biopsy; psychological distress; screening

Prostate cancer is a serious public health problem, motivating research to determine whether population screening is effective. The recent publication of two randomised controlled trials still leaves the benefits of screening uncertain and controversial (Andriole et al, 2009; Schröder et al, 2009), with the European Association of Urology currently not recommending screening as a public health policy (Abrahamsson et al, 2009). Regardless of the lack of evidence, prostate-specific antigen (PSA) testing in asymptomatic men continues to rise (Melia et al, 2004; Collin et al, 2008).

Uncertainties remain about the predictive validity of PSA tests, and their ability to identify tumours that will progress to cause morbidity and mortality (Frankel et al, 2003; Holmstrom et al, 2009). Arbitrary thresholds (commonly 3 or $4 \mathrm{ng} \mathrm{ml}^{-1}$ ) are used to recommend referral for biopsy. PSA levels are affected by measurement error and conditions other than prostate cancer, so it is not uncommon for PSA levels to rise and fall (Rosario et al, 2008). For these reasons, a high proportion of men with a raised

\footnotetext{
*Correspondence: Dr K Vedhara;

E-mail: kavita.vedhara@nottingham.ac.uk

Received I December 2009; revised 4 March 2010; accepted 17 March 2010; published online 6 April 2010
}

PSA go on to receive a negative biopsy result - for example, $75 \%$ of men with a PSA test of $\geqslant 3 \mathrm{ng} \mathrm{ml}^{-1}$ who had a biopsy in the European Randomised Study of Screening for Prostate Cancer (Schröder et al, 2009).

Consequently, many men who have a PSA test (and their physicians) may be left to cope with uncertain results. Increases in negative mood have been found in studies of women with abnormal but benign results for breast (Lowe et al, 1999; Aro et al, 2000) and ovarian (Andrykowski et al, 2004) cancer. Although studies of men undergoing PSA testing have shown no significant effect on anxiety for those receiving an abnormal PSA result (Essink-Bot et al, 1998; Brindle et al, 2006; Carlsson et al, 2007), it has been reported that those who receive a benign biopsy have thought and worried more about prostate cancer (McNaughtonCollins et al, 2004; Fowler et al, 2006; Katz et al, 2007). However, these latter studies were small and relied on unvalidated measures for these outcomes. We aimed to assess the prevalence and level of psychological distress and negative mood at several time-points during population-based testing for prostate cancer, focusing on men who received a negative biopsy result, using validated and standardised questionnaires. Baseline data were explored to investigate whether men vulnerable to heightened distress could be identified early in the testing process. 


\section{MATERIALS AND METHODS}

\section{Participants}

Participants in this study were men enrolled in the Prostate testing for cancer and Treatment (ProtecT) study, a randomised trial of treatment for localised prostate cancer (Donovan et al, 2003). Men aged 50-69 years were invited from general practices across nine sites in the United Kingdom to attend for PSA testing. Those with a raised PSA level $\left(\geqslant 3 \mathrm{ng} \mathrm{ml}^{-1}\right)$ were offered a transrectal ultrasound-guided biopsy carried out by an urologist to a standard 10 -core protocol at the local hospital. Men diagnosed with clinically localised cancer were eligible for randomisation to one of the three treatments. Between June 2007 and September 2008, men receiving a negative biopsy result (with no immediate requirement for a re-biopsy) were identified for this substudy, by local research nurses from eight of the UK sites.

Approval for the ProtecT study was obtained from Trent Multicentre Research Ethics Committee. Written informed consent was provided by all participants.

\section{Measures}

Mood and psychological distress were assessed at four time-points by patient-completed questionnaires: (1) when attending for the first PSA test (before the result was known); (2) when attending for biopsy (in clinic before the procedure); (3) within a few days of receiving the negative biopsy result (postal questionnaire, completed at home) and (4) $\sim 12$ weeks later (postal questionnaire, for those who returned a questionnaire at time-point 3) (see Figure 1). One reminder was posted if questionnaires were not returned within 10 working days.
Current states of mood were assessed by the Profile of Mood States - short form (POMS-SF) (Shacham, 1983), a 37-adjective checklist rated on a 5-point scale $(0=$ 'not at all' to $4=$ 'extremely'). Responses to items were totalled, providing six subscale scores for tension-anxiety (maximum score $=24$ ), depression-dejection (maximum score $=32$ ), anger-hostility (maximum score $=28$ ), fatigue-inertia (maximum score $=20$ ), vigour-activity (maximum score $=24$ ) and confusion-bewilderment (maximum score $=20)$. Distress was measured by the Impact of Events Scale (IES) (Horowitz et al, 1979); in which seven items formed an intrusion subscale and eight an avoidance subscale, scored $0=$ 'not at all', $1=$ 'rarely', $3=$ 'sometimes', $5=$ 'often', and collated to give an overall score (maximum score $=75$ ). Questions were adapted to assess the frequency of intrusive thoughts and avoidance of issues surrounding the specific event of that time-point: the PSA test, the biopsy, the negative biopsy result and, for the follow-up assessment, being tested for prostate cancer overall. For example: 'I tried not to think about the PSA blood test' (time-point 1); 'I tried not to think about going for my biopsy' (time-point 2); 'I tried not to think about getting my biopsy results' (time-point 3 ) and 'I tried not to think about being tested for prostate cancer' (time-point 4). Written instructions informed men to respond about their feelings during the past week, including that day. Both measures have previously been used in studies investigating the effect of cancer screening (Taylor et al, 2002; Andrykowski et al, 2004).

\section{Missing data}

Multiple responses to an individual item on the POMS questionnaire were considered as errors and treated as missing values. Single missing values within a subscale were replaced with the

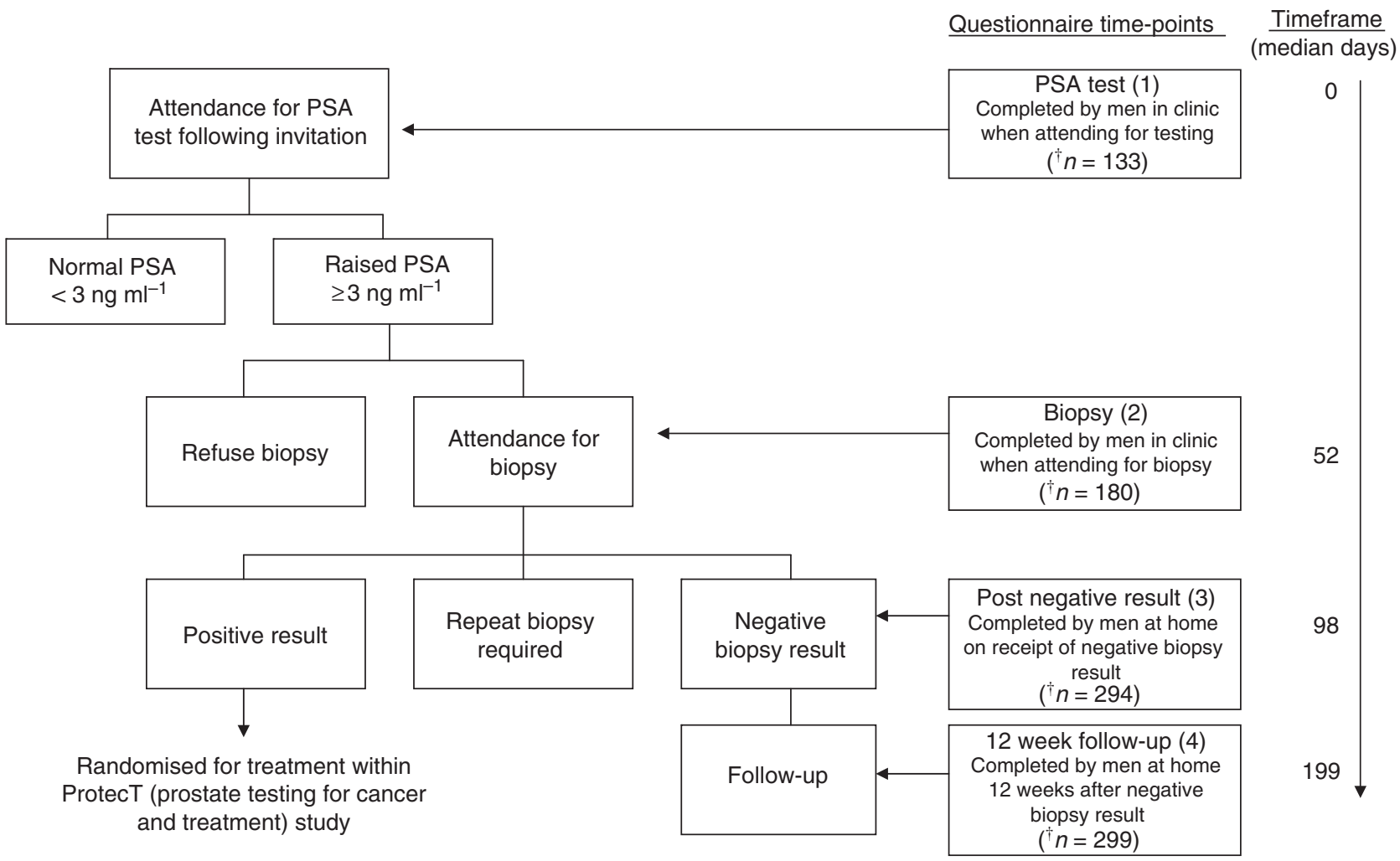

$\dagger$ Number of men with complete questionnaire data

Figure I Outline of study design and assessment time-points. 
individual's mean response to items within the rest of that subscale (184 imputations, $<1 \%$ of total responses). In cases of two or more missing values, no score was calculated for that POMS subscale. Missing items on the IES resulted in no subscale score or total score. This substudy was embedded in the ProtecT trial and as the POMS and IES were added in an amendment to the original protocol, some men identified with a negative biopsy result had completed time-points 1 and 2 before the measures were introduced, resulting in lower numbers of men completing the measures at earlier time-points (see Figure 1).

\section{Statistical analyses}

High levels of psychological distress were determined using established cutoff thresholds: for IES, a total score of $>19$ (Joseph, 2000); for POMS negative mood subscales, 1.5 s.d. above the mean at PSA testing (time-point 1) (Nyenhuis et al, 1999). Change in mood over time was examined in those men who completed all of the questionnaires they were sent $(n=195)$; this included men who had already undergone PSA testing and biopsy when this substudy started and so had their earlier questionnaire responses missing completely at random. T-tests compared the scores at PSA test for this cohort of men to those who completed questionnaires at PSA test but not all of the subsequent assessments. For longitudinal analyses, linear regression models with questionnaire subscale scores as outcome measures were fitted using Stata 10. Models compared questionnaire scores at the subsequent time-points to responses at PSA test (time-point 1). $P$-values were calculated using parametric bootstrap estimates of the s.e. (Davison and Hinkley, 1997). Confidence intervals (CIs) were calculated using the percentile bias corrected and accelerated bootstrap method. A total of 1999 bootstrap samples were obtained by re-sampling men from the study sample with replacement, so accommodating the repeated measures design and any non-normality in the distributions of outcome measure. Because of the extreme positive skew of IES scores, a sensitivity analysis used logistic regression of dichotomised scores (no distress symptoms/at least some symptoms).

A secondary analysis examined cases of heightened distress (IES total score) and high anxiety (POMS tension-anxiety score) at attendance for biopsy and after having received a negative biopsy result, and explored potential predictors: demographic (age, family history of prostate cancer and any cancer), clinical (PSA level, lower urinary tract symptoms: frequency, urgency, incontinence, nocturia, hesitancy and interference with everyday life) and psychological (baseline POMS anxiety and IES avoidance and intrusion subscale scores). Univariable logistic regression models were fitted to examine each of these 13 baseline measures in turn as a predictor of high distress and anxiety at later time-points in the testing process.

\section{RESULTS}

In total, 330 men were contacted after a negative biopsy result. Table 1 shows their clinical and demographic details. The response rate for postal questionnaires was $91.8 \%$ after the negative biopsy result (time-point 3 ) and $82.6 \%$ at the 12 -week follow-up (timepoint 4$)$. Non-responders were significantly younger than responders at both time-points ( $P=0.016, P=0.006$, respectively). After accounting for non-responders and missing responses on questionnaire items, data were available from 294 out of 330 and 229 out of 287 men, respectively (only those who responded at timepoint 3 were sent a follow-up questionnaire, and during one week men were not posted questionnaires due to an administrative error, thus reducing the denominator to 287). POMS and IES data were available for 133 out of 330 of the study sample at PSA assessment (time-point 1), and for 180 out of 330 at biopsy assessment (time-point 2) - smaller numbers due to introducing the measures part-way through the ProtecT study. Figure 1 shows average time (median number of days) between assessments.

Overall, rates of psychological distress (IES scores) and negative mood (POMS scores) were relatively low at all time-points, with around $80-95 \%$ of individuals reporting levels below the clinical threshold at each stage (Table 2). However, nearly one fifth of men (19.4\%) reported high levels of tension-anxiety at the time of attending for the biopsy (time-point 2), and $8.9 \%$ after the negative biopsy result (time-point 3 ). The proportion of men with a distress level of clinical concern was markedly higher at the time of biopsy compared with distress at the time of the PSA test $(19.3,0.8 \%$, respectively). This percentage decreased only slightly after the negative biopsy result (16.9\%), and $9.7 \%$ were distinctly distressed by the testing process after 12 weeks. Reports of high depressiondejection (7.5\%), anger-hostility (6.8\%), fatigue-inertia (12\%) and confusion-bewilderment $(8.3 \%)$ were most prevalent at the time of the PSA test, whereas they were $<5 \%$ by the 12 -week follow-up (Table 2 ).

Within the study sample, 195 men responded to all questionnaires they were sent, with POMS and IES scores missing for one or both of the first two assessments only if the man joined the study before these measures were introduced. These earlier assessments at time-points 1 and 2 were assumed to be missing at random, enabling changes in mood over the course of the testing process to be observed without confounding by determinants of non-response (Table 3). This cohort had similar clinical and demographic distributions to that of the complete sample (Table 1). At the time of the biopsy, a significant increase in tense and anxious moods was apparent (difference in mean: 2.07 ; $95 \% \mathrm{CI}$ $(1.35,2.83) ; P<0.001)$, and men experienced significantly more distress (difference in mean IES total score: 9.47; 95\% CI (6.97, 12.12); $P<0.001$ ). After receiving a negative biopsy result, scores for tense and anxious moods returned to levels similar to those recorded at the PSA test. However, reports of distress were significantly higher than at the time of the PSA test (difference in

Table I Clinical and demographic information for the whole study sample and the longitudinal cohort

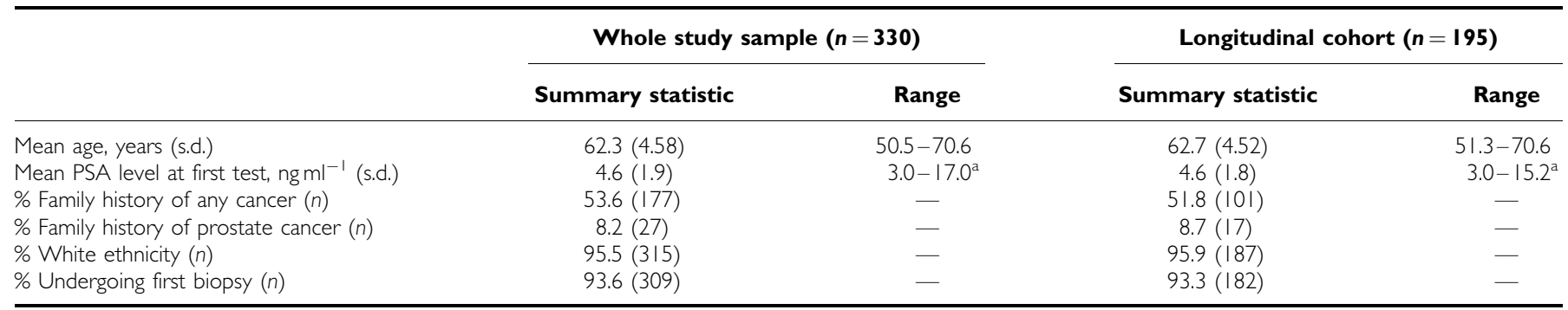

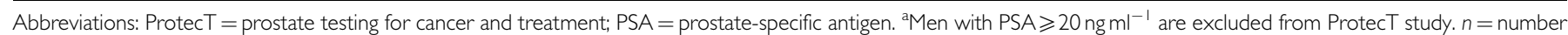
in sample. 
Table 2 Mean scores for negative moods and distress, and percentage of men with scores of clinical significance

\begin{tabular}{|c|c|c|c|c|c|c|c|c|}
\hline \multirow[b]{2}{*}{$\begin{array}{l}\text { Questionnaire } \\
\text { and subscale }\end{array}$} & \multicolumn{2}{|c|}{ PSA test (time-point I) } & \multicolumn{2}{|c|}{ Biopsy (time-point 2) } & \multicolumn{2}{|c|}{$\begin{array}{l}\text { Post-negative result } \\
\text { (time-point 3) }\end{array}$} & \multicolumn{2}{|c|}{$\begin{array}{l}\text { 12-week follow-up } \\
\text { (time-point 4) }\end{array}$} \\
\hline & $\begin{array}{l}\text { Mean } \\
\text { (s.d.) }\end{array}$ & $\begin{array}{l}\text { \% High scores } \\
(\mathbf{n} / \mathbf{N})\end{array}$ & $\begin{array}{l}\text { Mean } \\
\text { (s.d.) }\end{array}$ & $\begin{array}{l}\text { \% High scores } \\
(n / N)\end{array}$ & $\begin{array}{l}\text { Mean } \\
\text { (s.d.) }\end{array}$ & $\begin{array}{l}\text { \% High scores } \\
(n / N)\end{array}$ & $\begin{array}{l}\text { Mean } \\
\text { (s.d.) }\end{array}$ & $\begin{array}{l}\text { \% High scores } \\
(n / N)\end{array}$ \\
\hline POMS tension-anxiety & $3.77(3.48)$ & $10.5(14 / 133)$ & $5.07(4.11)$ & $19.4(35 / 180)$ & $3.38(3.75)$ & $8.9(26 / 292)$ & $2.39(2.89)$ & $4.8(11 / 229)$ \\
\hline Depression-dejection & $2.52(4.57)$ & $7.5(10 / 133)$ & $2.42(3.65)$ & $5.1(9 / 178)$ & $2.40(4.10)$ & $6.5(19 / 292)$ & $1.75(3.49)$ & $3.1(7 / 228)$ \\
\hline Anger-hostility & $2.94(3.56)$ & $6.8(9 / 132)$ & $2.89(3.37)$ & $5.6(10 / 179)$ & $2.40(3.43)$ & $6.2(18 / 292)$ & $1.89(2.68)$ & $3.9(9 / 229)$ \\
\hline IES distress (total score) & $2.35(4.43)$ & $0.8(1 / 129)$ & $11.74(13.76)$ & $19.3(33 / 171)$ & $9.51(12.32)$ & $16.9(49 / 290)$ & $4.88(8.82)$ & $9.7(22 / 227)$ \\
\hline
\end{tabular}

Abbreviations: IES = Impact of Events Scale; POMS = Profile of Mood States; PSA = prostate-specific antigen. ${ }^{\mathrm{a}}$ Thresholds for clinical scores (see text for definitions): POMS tension-anxiety 9.0, depression-dejection 9.4, anger-hostility 8.3, fatigue-inertia 10.9, confusion-bewilderment 6.6; IES distress I9.0. n/N= number of cases/number completing subscale. Data are cross-sectional at each assessment time-point, from the whole study sample.

Table 3 Mean scores for the longitudinal cohort (those who completed all the questionnaires they were sent)

\begin{tabular}{|c|c|c|c|c|c|c|c|c|c|}
\hline \multirow[b]{2}{*}{$\begin{array}{l}\text { Questionnaire } \\
\text { and subscale }\end{array}$} & \multicolumn{2}{|c|}{ PSA test (time-point I) } & \multicolumn{2}{|c|}{ Biopsy (time-point 2) } & \multicolumn{2}{|c|}{$\begin{array}{c}\text { Post-negative result } \\
\text { (time-point } 3 \text { ) }\end{array}$} & \multicolumn{2}{|c|}{$\begin{array}{l}\text { I2-week follow-up } \\
\text { (time-point 4) }\end{array}$} & \multirow[b]{2}{*}{$P$-value ${ }^{a}$} \\
\hline & $\begin{array}{l}\text { Mean } \\
\text { (s.d.) }\end{array}$ & $\begin{array}{l}\text { \% High scores } \\
(n / N)\end{array}$ & $\begin{array}{l}\text { Mean } \\
\text { (s.d.) }\end{array}$ & $\begin{array}{l}\text { \% High scores } \\
(n / N)\end{array}$ & $\begin{array}{l}\text { Mean } \\
\text { (s.d.) }\end{array}$ & $\begin{array}{l}\text { \% High scores } \\
(n / N)\end{array}$ & $\begin{array}{l}\text { Mean } \\
\text { (s.d.) }\end{array}$ & $\begin{array}{c}\text { \% High scores } \\
(n / N)\end{array}$ & \\
\hline POMS tension-anxiety & $2.95(2.83)$ & $4.6(3 / 66)$ & $5.02(4.31)$ & $19.1(25 /|3|)$ & $3.17(3.66)$ & $8.8(17 / 194)$ & $2.31(2.77)$ & $3.6(7 / 194)$ & $<0.001$ \\
\hline Depression-dejection & $1.72(2.57)$ & $1.5(1 / 65)$ & $2.38(3.65)$ & $5.5(7 / 128)$ & $1.99(3.62)$ & $5.2(10 / 191)$ & $1.60(3.07)$ & $2.1(4 / 191)$ & 0.086 \\
\hline Anger-hostility & $2.37(2.56)$ & $4.6(3 / 66)$ & $2.71(3.31)$ & $5.4(7 / 130)$ & $2.18(3.39)$ & $5.7(11 / 194)$ & $1.88(2.61)$ & $3.6(7 / 194)$ & 0.041 \\
\hline Fatigue-inertia & $3.42(3.22)$ & $3.0(2 / 66)$ & $3.17(3.38)$ & $4.6(6 /|3|)$ & $3.22(3.56)$ & $4.1(8 / 195)$ & $3.24(3.34)$ & $3.1(6 / 195)$ & 0.95 \\
\hline Confusion-bewilderment & $2.41(2.17)$ & $6.1(4 / 66)$ & $2.43(2.49)$ & $7.0(9 / 129)$ & $1.88(2.29)$ & $3.6(7 / 193)$ & $1.68(2.07)$ & $4.2(8 / 193)$ & 0.002 \\
\hline IES distress (total score) & $2.52(5.20)$ & $1.7(1 / 60)$ & $11.98(14.23)$ & $21.1(24 / 114)$ & $9.84(12.74)$ & $19.0(34 / 179)$ & $4.93(9.01)$ & $8.9(16 / 179)$ & $<0.001$ \\
\hline
\end{tabular}

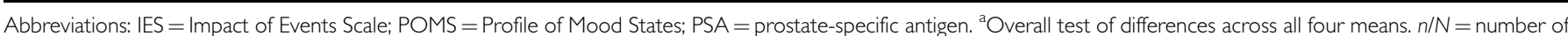
cases/number in sample.

Table 4 Predictor variables for high anxiety and psychological distress at biopsy, after receiving a negative biopsy result, and 12 weeks later

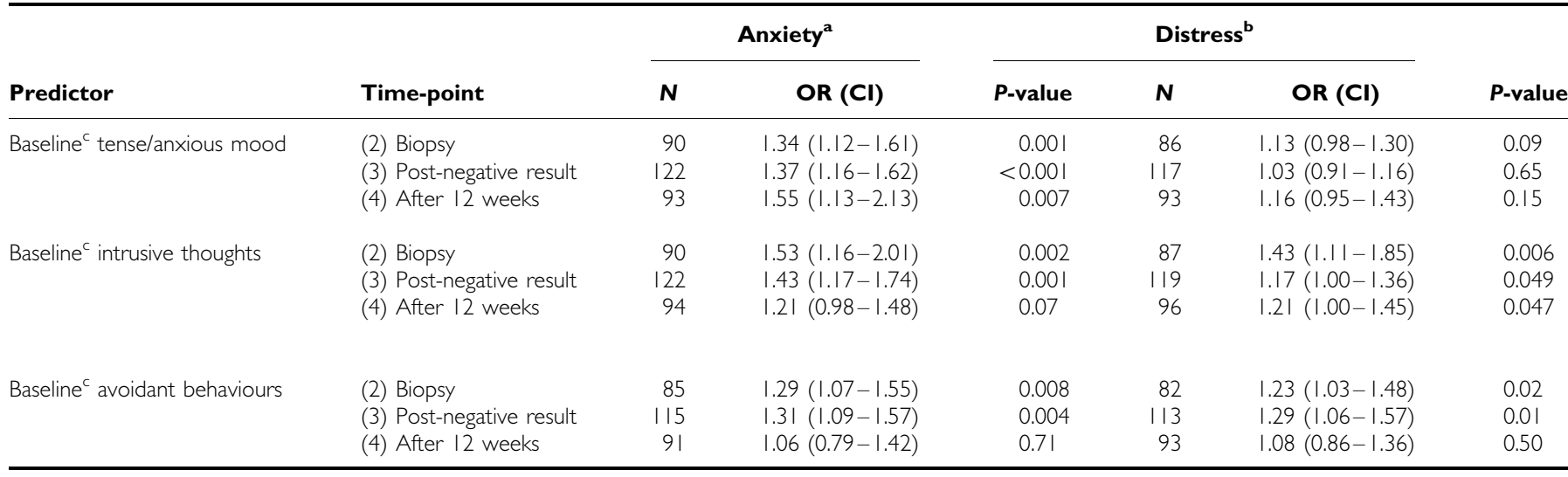

Abbreviations: $\mathrm{Cl}=95 \%$ confidence interval; OR = odds ratio; PSA = prostate-specific antigen. ${ }^{\mathrm{a} B a s e d}$ on Profile of Mood State tension-anxiety score. ${ }^{\mathrm{b}}$ Based on Impact of Events Scale total score. 'Baseline mood and distress is that measured at time of initial PSA testing.

mean: 7.32; 95\% CI (5.51, 9.52); $P<0.001)$. Approximately 12 weeks after having received a negative result (time-point 4), distress relating to prostate cancer testing remained more prevalent than distress at the time of the PSA test (difference in mean: 2.42 ; $95 \%$ CI $(0.50,1.15) ; P=0.009)$, with $8.9 \%$ of men $(16$ out of 179) reporting scores of clinical concern. For these IES results, logistic regression of dichotomised scores supported the same conclusions, although this sensitivity analysis suggested that the elevation at the 12-week follow-up assessment could have arisen by chance (odds ratio (OR): $1.42 ; 95 \%$ CI $(0.80,2.52)$; $P=0.23)$. Feelings of confusion-bewilderment were at a significantly lower level at the 12-week follow-up than at PSA testing (difference in mean: -0.73 ; 95\% CI $(-1.26,-0.25)$; $P=0.004)$. Additional analysis of the cohort of men with complete data available for all four of the assessment time-points $(n=66)$ was consistent with the results presented here and the same conclusions are supported.

None of the demographic or clinical factors recorded at baseline significantly predicted high distress and anxiety levels at the subsequent study time-points (with the exception of urinary hesitancy: OR: $4.76 ; 95 \%$ CI $(1.95,11.62) ; P=0.001)$, although psychological factors did (Table 4). 
For post hoc analysis to explore other possible reasons why men may experience higher distress levels 12 weeks after biopsy, we retrieved information on any further biopsies the study men had undergone. Twenty-three men were found to have had a second biopsy before being sent their 12-week follow-up questionnaires, of which 17 men returned data for this assessment (73.9\%). The mean IES total scores (s.d., number of men with high scores/ number completing measure) for these 17 men were $1.29(2.98,0$ out of 7$)$ at time-point $1 ; 5.00(4.38,0$ out of 6$)$ at time-point $2 ; 9.12$ $(10.75,3$ out of 17) at time-point 3 and $8.53(11.31,4$ out of 15) at time-point 4 . There was no significant difference between IES scores at the 12-week follow-up assessment for those who had a repeat biopsy and those who did not $(P=0.096)$. Of the total number of men from the complete cohort who had high distress at the 12-week follow-up assessment, $18 \%$ (4 out of 22) had undergone a further biopsy.

\section{DISCUSSION}

This study shows that most men seem to cope well with a raised PSA result followed by a negative biopsy. Mean scores for all the questionnaire scales were relatively low with regard to the thresholds for clinical significance and the maximum possible ranges. However, nearly $20 \%$ experienced high levels of tension-anxiety and psychological distress at the time of the biopsy, as well as $8.9 \%$ with high tension-anxiety and $16.9 \%$ with psychological distress immediately after the receipt of a negative biopsy result. These findings were substantiated in the longitudinal cohort. Men exhibited significant increases in distress and tense and anxious moods from baseline to the time of the biopsy, which then declined somewhat after receipt of a negative biopsy result, before returning to much lower levels 12 weeks later. However, distress was significantly more prevalent at all of the subsequent time-points compared with distress at the time of the PSA test, and almost $10 \%$ reported distress levels of clinical concern at the 12-week follow-up. Baseline levels of mood were found to predict levels of distress and anxiety at the time of biopsy, after the negative biopsy result and 12 weeks later.

The present investigation was conducted within the ProtecT study, enabling large numbers of men based in the community to participate. This detailed quantitative study of the emotional consequences of prostate cancer testing is the first study of its kind in the United Kingdom, using more detailed psychological measures and using a longer follow-up time than one other study conducted in the Netherlands (Essink-Bot et al, 1998). However, the study encompasses some limitations. The 'baseline' measures were at the time of the initial PSA test, and it could be argued that negative mood may already have been elevated at this time, although an earlier investigation in the ProtecT cohort showed no difference in depressed or anxious mood between men who responded to an invitation for PSA testing and those who did not (Avery et al, 2008b). All men had self-selected to take part in the study initially, which may influence their psychological response to being tested. An important issue when interpreting the findings from the longitudinal cohort was that they were a smaller and select group of men. This had the advantage of exploring unconfounded comparisons across time, although external validity was weakened as men who failed to respond were excluded. Caution is therefore needed before generalising these results to a wider population. The statistical methodology chosen did, however, make use of the maximum data available. The longitudinal cohort included those men who had already undergone their biopsy just before the current substudy started, but who completed both of their post-biopsy questionnaires when invited to do so. These men did not complete substudy questionnaires at time-points 1 and 2, but as these data are missing completely at random, their inclusion in the longitudinal cohort improves precision without introducing bias. Nevertheless, we acknowledge that these results could have been strengthened by a longer recruitment period enabling a larger longitudinal cohort with data available at all four assessments.

The study findings are reassuring in that most men seemed to cope well with the seemingly equivocal result of a raised PSA followed by a negative biopsy result. However, it remains of concern that nearly $20 \%$ suffered high levels of distress at the time of biopsy and nearly $17 \%$ after having received a negative result. In an earlier longitudinal study of men being screened for prostate cancer, Gustafsson et al (1995) reported that cortisol level (indicating the degree of emotional stress) was highest immediately before being informed of the biopsy result, although levels decreased somewhat 2 weeks later in those who received a benign biopsy result. Other studies have concluded that testing for prostate cancer had little or no effect on men's psychological health (Brindle et al, 2006; Awsare et al, 2008). These studies relied on the Hospital Anxiety and Depression Scale (HADS) (Zigmond and Snaith, 1983), which was designed to detect clinical cases of anxiety and depression. Both studies commented on the low sensitivity of the HADS in the context of prostate cancer testing. In addition, a longitudinal Dutch screening study reported no significant adverse effects on psychological health after receipt of a negative biopsy result (Essink-Bot et al, 1998). This study used a general measure for anxiety, which also may not have been sensitive enough to identify men's concerns in the context of prostate cancer screening. The findings reported here confirm that more detailed, specific measures (e.g. POMS and IES) better reflect the changes in mood and distress in some men as apparent in an earlier qualitative study (Avery et al, 2008a).

The IES statements at each of the first three time-points were tailored to focus on specific aspects current for that stage of the testing process, for example at time-point 1: 'I had dreams about the PSA blood test'. The adapted IES statements at the 12-week follow-up (time-point 4) referred to the complete testing process for example 'I had dreams about being tested for prostate cancer'. In contrast, the POMS consisted of an adjective list of emotions with no direct reference to particular events in time. The pattern of mood levels over time was similar whether measured by the IES or POMS, although POMS scores seemed to return to pre-PSA levels sooner. At every time-point, men were asked to respond with regard to how they had felt during the preceding week. However, at the 12-week follow-up, the prompt to think about the complete testing process may have triggered memories of earlier mood states. This could have influenced men's responses, rather than just reporting on recent intrusive thoughts and avoidant behaviours that had troubled them during the previous week. It is possible that distress in some men 12 weeks after the biopsy could be due to the knowledge that a negative biopsy result does not necessarily indicate the 'all clear'. Further research, preferably qualitative, is required to explore this issue and other explanations for distress after a negative biopsy result.

It has previously been shown that older age, a positive family history, and a higher PSA level did not predict anxiety in men during testing for prostate cancer (Macefield et al, 2009). In contrast here, baseline psychological mood was predictive of distress and anxiety at later stages of the testing process. This reflects the findings of the Dutch study, where initial high anxiety levels were maintained during testing (Essink-Bot et al, 1998), and supports that baseline psychological factors can continue to be predictive of distress and anxiety after a longer period after screening.

The findings of this study have clear practical relevance. Despite its controversy, PSA testing is widespread. These results, particularly that high levels of distress may be encountered 
by some men, should be included in information presented to men by GPs before they consent to receiving a test. For men undergoing testing, whether as part of screening, or in primary or secondary care, the concomitant collection of POMS and IES data could be used to identify men who are experiencing tension-anxiety and early distress symptoms at the time of the PSA test, and thus identify those who might benefit from additional support and information to prevent this developing into distress later on (see also Essink-Bot et al, 1998; Awsare et al, 2008).

The intention of this study was to capture men's psychological experiences during prostate cancer testing. Focusing on those who received a negative biopsy result, it revealed that the majority of men who undergo testing are not significantly adversely affected, although some men do find the process distressing. Men should be informed of the risk of distress before agreeing to a PSA test.

\section{REFERENCES}

Abrahamsson PA, Artibani W, Chapple CR, Wirth M (2009) European Association of urology position statement on screening for prostate cancer. Eur Urol 56(2): 270-271

Andriole GL, Grubb RLI, Buys SS, Chia D, Church TR, Fouad MN, Gelmann EP, Kvale PA, Reding DJ, Weissfeld JL, Yokochi LA, Crawford ED, O'Brien B, Clapp JD, Rathmell JM, Riley TL, Hayes RB, Kramer BS, Izmirlian G, Miller AB, Pinsky PF, Prorok PC, Gohagan JK, Berg CD (2009) Mortality results from a randomized prostate-cancer screening trial. N Engl J Med 360(13): 1310-1319

Andrykowski MA, Boerner LM, Salsman JM, Pavlik E (2004) Psychological response to test results in an ovarian cancer screening program: a prospective, longitudinal study. Health Psychol 23(6): 622-630

Aro AR, Pilvikki Absetz S, van Elderen TM, van der Ploeg E, van der Kamp LJTh (2000) False-positive findings in mammography screening induces short-term distress - breast cancer-specific concern prevails longer. Eur J Cancer 36: 1089-1097

Avery KNL, Blazeby JM, Lane JA, Neal DE, Hamdy FC, Donovan JL (2008a) Decision-making about PSA testing and prostate biopsies: a qualitative study embedded in a primary care randomised trial. Eur Urol 53: $1186-1193$

Avery KNL, Metcalfe C, Blazeby JM, Lane JA, Neal D, Hamdy FC, Donovan J (2008b) Prostate-specific antigen testing and prostate biopsy: are selfreported lower urinary tract symptoms and health-related quality of life associated with the decision to undergo these investigations? BJU Int 102(11): $1629-1633$

Awsare NS, Green JSA, Aldwinckle B, Hanbury DC, Boustead GB, McNicholas TA (2008) The measurement of psychological distress in men being investigated for the presence of prostate cancer. Prostate Cancer Prostatic Dis 11(4): $384-389$

Brindle LA, Oliver SE, Dedman D, Donovan JL, Neal DE, Hamdy FC, Lane JA, Peters TJ (2006) Measuring the psychosocial impact of populationbased prostate-specific antigen testing for prostate cancer in the UK. BJU Int 98: $777-782$

Carlsson S, Aus G, Wessman C, Hugosson J (2007) Anxiety associated with prostate cancer screening with special reference to men with a positive screening test (elevated PSA) - results from a prospective, populationbased, randomised study. Eur J Cancer 43: 2109-2116

Collin SM, Martin RM, Metcalfe C, Gunnell D, Albertsen PC, Neal D, Hamdy F, Stephens P, Lane JA, Moore R, Donovan J (2008) Prostatecancer mortality in the USA and UK in 1975-2004: an ecological study. Lancet Oncol 9(5): 445-452

Davison AC, Hinkley DV (1997) Bootstrap Methods and Their Application. Cambridge University Press: Cambridge

Donovan JL, Hamdy FC, Neal DE, Peters TJ, Oliver SE, Brindle LA, Jewell D, Powell P, Gillatt D, Dedman D, Mills N, Smith MA, Noble S, Lane JA (2003) Prostate testing for cancer and treatment (ProtecT) feasibility study. Health Technol Assess 7(14): 1-49

Essink-Bot M-L, de Koning HJ, Nijs HGT, Kirkels WJ, van der Maas PJ, Schröder FH (1998) Short-term effects of population-based screening for prostate cancer on health-related quality of life. J Natl Cancer Inst 90: $925-931$

\section{ACKNOWLEDGEMENTS}

We acknowledge the invaluable contribution of members of the ProtecT study research group: Prasad Bollina, Sue Bonnington, Lynne Bradshaw, James Catto, Debbie Cooper, Michael Davis, Andrew Doble, Alan Doherty, Garrett Durkan, Emma Elliott, David Gillatt, Pippa Herbert, Peter Holding, Joanne Howson, Mandy Jones, Roger Kockelbergh, Howard Kynaston, Teresa Lennon, Norma Lyons, Hing Leung, Malcolm Mason, Hilary Moody, Philip Powell, Alan Paul, Stephen Prescott, Derek Rosario, Patricia O'Sullivan, and Pauline Thompson. The ProtecT study is supported by the NIHR Health Technology Assessment Programme (projects 96/20/06, 96/20/99); ISRCTN 20141297. The current study was funded by an additional Cancer Research UK Small Grant: Population and Behavioural Sciences Committee (C11053/A8086). The views and opinions expressed therein are those of the authors and do not necessarily reflect those of the Department of Health. The funders had no involvement in this work.
Fowler FJ, Barry MJ, Walker-Corkery B, Caubet J-F, Bates DW, Lee JM, Hauser A, McNaughton-Collins M (2006) The impact of a suspicious prostate biopsy on patients' psychological, socio-behavioural, and medical care outcomes. J Gen Intern Med 21: 715-721

Frankel S, Davey Smith G, Donovan J, Neal D (2003) Screening for prostate cancer. Lancet 361: $1122-1128$

Gustafsson O, Theorell T, Norming U, Perski A, Ohstrom M, Nyman CR (1995) Psychological reactions in men screened for prostate-cancer. $\mathrm{Br} \mathrm{J}$ Urol 75(5): $631-636$

Holmstrom B, Johansson M, Bergh A, Stenman UH, Hallmans G, Stattin P (2009) Prostate specific antigen for early detection of prostate cancer: longitudinal study. BMJ 339: b3537

Horowitz M, Wilner N, Alvarez MA (1979) Impact of event scale: a measure of subjective stress. Psychosom Med 41(3): 209-218

Joseph S (2000) Psychometric evaluation of Horowitz's impact of events scale: a review. J Trauma Stress 13(1): $101-113$

Katz DA, Jarrard DF, McHorney CA, Hillis SL (2007) Health perceptions in patients who undergo screening and workup for prostate cancer. Urology 69(2): 215-220

Lowe JB, Balanda KP, Del Mar C, Hawes E (1999) Psychological distress in women with abnormal findings in mass mammography screening. Cancer 85: $1114-1118$

Macefield RC, Lane JA, Metcalfe C, Down L, Neal DE, Hamdy FC, Donovan JL (2009) Do the risk factors of age, family history of prostate cancer or a higher prostate specific antigen level raise anxiety at prostate biopsy? Eur J Cancer 45(14): 2569-2573

McNaughton-Collins M, Fowler FJ, Caubet J-F, Bates DW, Lee JM, Hauser A, Barry MJ (2004) Psychological effects of a suspicious prostate cancer screening test followed by a benign biopsy result. Am J Med 117: 719-725

Melia J, Moss S, Johns L (2004) Rates of prostate-specific antigen testing in general practice in England and Wales in asymptomatic and symptomatic patients: a cross-sectional study. BJU Int 94(1): $51-56$

Nyenhuis DL, Yamamoto C, Luchetta T, Terrien A, Parmentier A (1999) Adult and geriatric normative data and validation of the profile of mood states. J Clin Psychol 55(1): 79-86

Rosario DJ, Lane JA, Metcalfe C, Catto JW, Dedman D, Donovan JL, Neal DE, Hamdy FC, ProtecT SG (2008) Contribution of a single repeat PSA test to prostate cancer risk assessment: experience from the ProtecT study. Eur Urol 53(4): $777-784$

Schröder FH, Hugosson J, Roobol MJ, Tammela TLJ, Ciatto S, Nelen V, Kwiatkowski M, Lujan M, Lilja H, Zappa M, Denis LJ, Recker F, Berenguer A, Maattanen L, Bangma CH, Aus G, Villers A, Rebillard X, van der Kwast T, Blijenberg BG, Moss SM, de Koning HJ, Auvinen A (2009) Screening and prostate-cancer mortality in a randomized European study. N Engl J Med 360(13): 1320-1328

Shacham S (1983) A shortened version of the profile of mood states. J Pers Assess 47(3): $305-306$

Taylor KL, Shelby RA, Kerner J, Redd W, Lynch J (2002) Impact of undergoing prostate carcinoma screening on prostate carcinoma-related knowledge and distress. Cancer 95: 1037-1044

Zigmond AS, Snaith RP (1983) The hospital anxiety and depression scale. Acta Psychiatr Scand 67(6): $361-370$ 